\title{
Effects of a Chelate (DTPA) on Cucumber Growth and Soil Chemical Properties in Nutrient-accumulated Soil of Polytunnel Greenhouse
}

\author{
Myung Sook Kim*, Yoo Hak Kim, Seong Soo Kang, Myung Suk Kong, \\ Byung Keun Hyun, and Chang Hoon Lee \\ Soil \& Fertilizer Management Division, National Academy of Agricultural Science, Suwon 441-707, Korea
}

(Received: November 19 2013, Accepted: December 16 2013)

This study was conducted to evaluate the effects of a chelating agent on cucumber growth and changes in soil nutrients availability in polytunnel greenhouse fields. Diethylene triamine penta acetic acid (DTPA) was selected as a chelating agent. Two experiments were caried out as follows: i) For field experiment in the autumn season of 2010, each plot was treated by varying the concentration and the number of times being applied with DTPA; [DTPA (0.5 mM, 1 time/3 months), DTPA ( $0.06 \mathrm{mM}, 1$ time/1 week), DTPA (0.13 mM, 1 time/2 weeks), DTPA $(0.06 \mathrm{mM}, 1$ time/1 week $)+\mathrm{N}]$. Conventional practice was also investigated. ii) In the spring and summer seasons of 2011, each plot was treated by varying the concentration $(0,0.06,0.13,0.19$ mM) of DTPA, chemical fertilizers (NPK), and combination of chemical fertilizers and DTPA $0.06 \mathrm{mM}$. The fruit yields of cucumber and soil chemical properties had no significant differences between treatments. However, in the spring season of 2011, DTPA $0.06 \mathrm{mM}$ plot added 1 time per 2 weeks increased the yield of cucumber, but caused the reduction of yield in next cultivation season. This result showed that excess use of DTPA can cause the damage of crop growth. The inorgainc contents such as $\mathrm{Ca}$ and $\mathrm{Mg}$ absorbed by cucumber plant had significant differences between DTPA $0.19 \mathrm{mM}(2$ times/1 week) and fertilizers plus DTPA treatments [DTPA $0.06 \mathrm{mM}$ (2 times/1 week) + 1/2 NPK, DTPA $0.06 \mathrm{mM}(2$ times/1 week $)+$ NPK]. The input cost of fertilizers was saved when the concentration and the number of times added with DTPA was 0.06 $\mathrm{mM}$ and 1 time a week, respectively. This treatment used $67 \%$ less of applied fertilizers cost than the plot of conventional practice did. Thus, this research suggested that the application of DTPA $0.06 \mathrm{mM}$ by 1 time a week can be effective for sustainability of crop production and reduction of fertilizers usage in polytunnel greenhouse.

Key words: Chelating agents, Diethylene tetramine penta acetic acid, Cucumber, Nutrients accumulation, Farm field

Fresh weight and number of fruits in cucumber plants at soils treated with various concentrations of DTPA in 2010.

\begin{tabular}{lcccc}
\hline \multicolumn{1}{c}{ Treatments } & $\begin{array}{c}\text { Weight of fresh } \\
\text { fruit/20 plants }\end{array}$ & $\begin{array}{c}\text { Relative } \\
\text { index }\end{array}$ & $\begin{array}{c}\text { Number of } \\
\text { fresh fruit/20 plants }\end{array}$ & $\begin{array}{c}\text { Relative } \\
\text { index }\end{array}$ \\
\hline & $\mathrm{kg}$ & $\%$ & & $\%$ \\
Control & $42 \pm 10 \mathrm{a}^{\dagger}$ & 100 & $232 \pm 56 \mathrm{a}$ & 100 \\
Conventional practice & $39 \pm 10 \mathrm{a}$ & 93 & $217 \pm 45 \mathrm{a}$ & 94 \\
DTPA(0.5 mM, 1 time/3 months) & $41 \pm 12 \mathrm{a}$ & 98 & $227 \pm 60 \mathrm{a}$ & 98 \\
DTPA(0.06 mM, 1 time/1 week) & $60 \pm 23 \mathrm{a}$ & 143 & $273 \pm 34 \mathrm{a}$ & 118 \\
DTPA(0.13 mM, 1 time/2 weeks) & $49 \pm 9 \mathrm{a}$ & 117 & $271 \pm 47 \mathrm{a}$ & 117 \\
DTPA(0.06 mM, 1 time/1 week) $+\mathrm{N}^{\top}$ & $47 \pm 8 \mathrm{a}$ & 112 & $260 \pm 43 \mathrm{a}$ & 112 \\
\hline
\end{tabular}

'Duncan's multiple range test $(\mathrm{p}<0.05)$

${ }^{ \pm}$Relative yield of control treatment

${ }^{\mathrm{T}} \mathrm{N}$ means nitrogen fertilizer

*Corresponding author : Phone: +82312900329, Fax:+82312900208, E-mail: msk74@korea.kr

${ }^{\S}$ Acknowledgement: this study was conducted by support of NAAS research and development project(project number: PJ007434072013). 


\section{Introduction}

킬레이트제는 자연상태에서 존재하는 물질이며 (Abdulla and Smith, 1963), 금속 이온과 2자리 이상으로 배위결합을 하여 고리구조의 모양을 만드는 리간드을 말한다 (Tuntiwiwut, 1982). 킬레이트제는 천연킬레이트제와 합성킬레이트제가 있 고 (Bray and Weil, 2008), 토양입자에 고정된 양분인 양이 온들을 토양입자로부터 분리시키고, 뿌리근처로 양이온을 자유롭게 이동시켜 식물뿌리가 양이온을 잘 흡수하게 하는 역할을 한다. 그리고 양이온과 결합되어 있던 음이온인 인 산성분의 흡수도 좋아지게 하며, 알루미늄과 같은 금속이온 들이 나타내는 작물독성을 감소시켜 주는 역할을 한다.

국외에서의 합성킬레이트제는 오래전부터 토양의 미량원 소 분석 (Lindsay and Norvell, 1978)과 중금속의 오염물질 을 제거 (Hong et al., 1999; Cao et al., 2007; Palmaa et $\mathrm{al}$, , 2007)하는데 주로 사용되었으며, 식물의 미량원소를 공 급하는 데 많이 이용되었다 (Weinstein et al., 1954; Brown et al., 1960; Abdulla and Smith, 1963; Wallace, 1963, Wallace et al., 1974).

국내에서는 합성킬레이트제가 오염된 토양의 중금속을 제거하는 세척제로서 $\mathrm{Cu}$ 및 $\mathrm{Zn}$ 을 제거하는데 효과적이라고 하였고 (Lee et al., 2012), 식물의 중금속 흡수 촉진제 (Oh et al., 2012), 토양 중 석유 물질을 제거하는 기술에 사용되 었다 (Nam et al., 2009). 또한, 토양이나 양액에서 작물재배 시 $\mathrm{Fe}$ 과 $\mathrm{Ca}$ 등의 성분을 킬레이트제에 붙여 이러한 성분의 흡수를 향상시키는 연구 (Lee et al., 2011; Jang et al., 2012) 에 이용되어 왔다. Kim et al. (2012)은 시설재배지에 합성킬 레이트제를 투입하여 집적된 염류 중 양분을 킬레이트화하여 작물의 흡수효율을 향상시키는 연구에 사용하였다.

우리나라 시설재배 토양의 전기 전도도 $(\mathrm{EC})$, 치환성 칼 슘 $(\mathrm{Ex} . \mathrm{Ca})$ 은 증가하는 경향이었고, 2012년 시설재배지의 $\mathrm{EC}$, 유효인산 $\left(\mathrm{Av} . \mathrm{P}_{2} \mathrm{O}_{5}\right)$, 치환성 칼륨 $(\mathrm{Ex} . \mathrm{K}), \mathrm{Ex} . \mathrm{Ca}$, 치 환성 마그네슘 $(\mathrm{Ex} . \mathrm{Mg})$ 은 각각 적정범위 상한보다 횔씬 높 은 수준이다 (RDA., 2013). 시설재배지에 집적된 염류문제 를 해결하는 방법은 기존에 많이 연구되었고, 대표적인 방 법으로 객토, 심토반전, 유기물 투입, 흡비작물 또는 녹비작 물의 윤작, 환수제염 등이 주로 소개되었다 (RDA., 2008).
그러나, 객토는 토양구입과 인건비에 비용이 많이 소요되 며, 흡비작물 또는 녹비작물의 재배는 한 작기의 작물재배 를 포기해야 하는 단점이 지적되고 있다. 특히 환수제염의 기술은 시설의 구조가 대형화되고 고정화되는 조건에서는 효과가 적고, 시간이 많이 소요되며, 염류가 수계로 흘러들 어갈 경우 환경오염의 우려가 제기되고 있다. 따라서, 자금 회전이 급한 시설농업 특성상 기존 방법은 시간이 많이 소 요되고 작물재배를 중단해야 한다는 문제점 때문에 활용상 제한점이 있다.

따라서 지금까지 제안된 다양한 염류해결 방법에 대하여 이들의 단점을 해결할 새로운 방법을 모색할 필요가 있다. 본 연구에서는 염류가 집적된 시설오이 재배 토양에서 킬레 이트제 처리 시 토양화학성 변화와 오이 생육에 미치는 효 과를 분석하여 농가 포장에서의 활용성을 검토하고자 수행 하였다.

\section{Materials and Methods}

2010년 가을작기 오이재배 본 실험은 2010년에 충남 천안시 동남구 화계리에 소재한 농가의 시설재배 하우스 포 장에서 수행되었다. 토양의 화학성은 오이재배를 위한 시설 재배지의 적정 비옥도에 기준 (NIAST, 2006)보다 EC가 2.5 배, $\mathrm{Av} . \mathrm{P}_{2} \mathrm{O}_{5}$ 과 Ex. $\mathrm{K}$ 은 2.1배, Ex. $\mathrm{Ca}$ 은 2.0배, Ex. $\mathrm{Mg}$ 는 1.8 배, $\mathrm{NO}_{3}-\mathrm{N}$ 은 3.3배로 높았다 (Table 1). 킬레이트제는 Kim et al. (2013)의 실험에서 처리효과가 높았던 DTPA를 사 용하였고, 처리구는 구당 면적이 $18 \mathrm{~m}^{2}$ 이고, 무비구 (Control), 농가관행구 (Conventional practice, N-K발효액비-인산: 105 $\mathrm{kg} / \mathrm{ha}$ ), DTPA $0.5 \mathrm{mM}$ (1 time/ 3 months), DTPA $0.06 \mathrm{mM}$ (1 time/1 week), DTPA $0.13 \mathrm{mM}$ (1 time/ 2 weeks), DTPA $0.06 \mathrm{mM}$ (1 time/1 week) + N (197kg/ha)이며, 완전임의배 치 3반복으로 처리하였다. 시험작물은 시설재배 오이 (Cucumis sativas L., 신정품)를 선정하였고, 9월 5일에 정식하여 12 월 2일까지 수확하였다.

2011년 봄 여름작기 오이재배 2010년 실험한 충남 천안시 동남구 화계리 농가의 시설재배 하우스 내에 인근

Table 1. Chemical properties of polytunnel house soil used at field experiment in 2010 and 2011.

\begin{tabular}{|c|c|c|c|c|c|c|c|c|c|c|}
\hline \multirow{2}{*}{ Soil } & \multirow{2}{*}{$\mathrm{pH}$} & \multirow{2}{*}{$\mathrm{EC}$} & \multirow{2}{*}{$\mathrm{OM}$} & \multirow{2}{*}{ Av. $\mathrm{P}_{2} \mathrm{O}_{5}$} & \multicolumn{4}{|c|}{ Ex. cation } & \multirow{2}{*}{$\mathrm{NO}_{3}-\mathrm{N}$} & \multirow{2}{*}{$\mathrm{NH}_{4}-\mathrm{N}$} \\
\hline & & & & & $\mathrm{K}$ & $\mathrm{Ca}$ & $\mathrm{Mg}$ & $\mathrm{Na}$ & & \\
\hline & $1: 5$ & $\mathrm{dS} \mathrm{m}^{-1}$ & $\mathrm{~g} \mathrm{~kg}^{-1}$ & $\mathrm{mg} \mathrm{kg}^{-1}$ & |------------ & $-\mathrm{cmol}_{\mathrm{c}}$ & $\mathrm{kg}^{-1}$ & ------ & ------ mg & $g^{-1}------$ \\
\hline Soil of 2010 & 5.9 & 5.00 & 29 & 954 & 1.58 & 11.0 & 3.2 & 0.42 & 442 & 83 \\
\hline Soil of 2011 & 6.0 & 8.58 & 33 & 1,283 & 1.86 & 13.7 & 4.5 & 0.97 & 490 & 12 \\
\hline Optimal range $^{\dagger}$ & $6.0 \sim 6.5$ & $\leq 2.00$ & $20 \sim 30$ & $400 \sim 500$ & $0.70 \sim 0.80$ & $5.0 \sim 6.0$ & $1.5 \sim 2.0$ & - & $70 \sim 200$ & - \\
\hline
\end{tabular}

${ }^{\dagger}$ Growth of cucumber 
포장에서 수행되었다. 토양의 화학성은 오이재배를 위한 시 설재배지의 적정 비옥도에 기준 (NIAST, 2006)보다 EC가 4.3 배, Av. $\mathrm{P}_{2} \mathrm{O}_{5}$ 2.6배, Ex. K은 6.8배, Ex. Ca은 2.5배, Ex. $\mathrm{Mg}$ 는 2.6배, $\mathrm{NO}_{3}-\mathrm{N}$ 은 3.6배로 높았다 (Table 1). 처리구는 구당 면적이 $14 \mathrm{~m}^{2}$ 이고, 무처리 (Control), DTPA $(0.06 \mathrm{mM}$, $0.13 \mathrm{mM}, 0.19 \mathrm{~m}$ ), DTPA와 3요소의 혼합구 (DTPA $0.06 \mathrm{mM}$ + 1/2 NPK: $145-35-125 \mathrm{~kg} / \mathrm{ha}), 3$ 요소 처리구의 $1 / 2$ 량 (1/2 $\mathrm{NPK}$ ), 3요소 처리구 (NPK: 290-70-250 kg/ha), DTPA와 3 요소량 (DTPA $0.06 \mathrm{mM}+\mathrm{NPK}$ )을 완전임의배치 3 반복으로 처리하였다. 시험작물은 시설재배 오이 (Cucumis sativas L. 신정품)를 선정하였고, 2월 7일에 정식하여 7월 4일까지 수확하였고, 다시 7월 6일에 정식하여 9월 2일까지 수확하 였다.

토양 및 식물체 분석 $\mathrm{pH}$ 와 $\mathrm{EC}$ 는 토양과 증류수의 비 율을 1:5로 추출하여 측정하였고, 토양유기물은 Tyurin법, 유효인산 $\left(\mathrm{Av}_{\cdot} \mathrm{P}_{2} \mathrm{O}_{5}\right)$ 은 Lancaster법으로 $720 \mathrm{~nm}$ 에서, 유효 규산은 $1 \mathrm{M} \mathrm{NaOAc}(\mathrm{pH} 4.0)$ 용액으로 추출하여 $700 \mathrm{~nm}$ 에서 비색계 (U-3000, Hitachi)로 측정하였다. 치환성 양이온은 $1 \mathrm{M} \mathrm{NH}_{4} \mathrm{OAc}(\mathrm{pH}$ 7.0) 완충용액으로 추출하여 유도결합 플 라즈마 발광광도계 (ICP-OES, GBC)으로 측정하였다. 오이 는 건조 후 분쇄한 시료를 $0.5 \mathrm{~g}$ 칭량하고 conc. $\mathrm{H}_{2} \mathrm{SO}_{4}$ 을 10 $\mathrm{mL}$ 와 $50 \%$ 의 $\mathrm{HClO}_{4} 10 \mathrm{~mL}$ 를 가하여 분해한 후 여과하여 총 질소 $(\mathrm{T}-\mathrm{N})$ 은 킬달증류방법으로 $\mathrm{P}, \mathrm{K}, \mathrm{Ca}, \mathrm{Mg}, \mathrm{Fe}, \mathrm{Cu}$, $\mathrm{Mn}, \mathrm{Zn}, \mathrm{Al}$ 등을 $\mathrm{ICP}-\mathrm{OES}$ 로 측정한 후 농도를 측정하였다 (NIAST, 2000).

통계분석 SAS 프로그램 (v. 9.2)를 사용하여 킬레이트 제 처리별 오이의 수량, 무기성분 흡수량의 차이를 비교하 기 위해 분산분석을 실시하였고, 처리간 차이는 던컨의 다 중범위 검정 (DMRT)으로 분석하였다.

\section{Results and Discussion}

2010년 가을작기 재배 처리구들 중에서 생산된 오이 의 총 수량과 상대수량지수는 Table 2 와 같았고, 처리구별 로 통계적인 차이가 없었다. 그러나 처리간에 오이 무게의 상대수량 지수는 DTPA $0.06 \mathrm{mM}$ (1 time/ week) > DTPA $0.13 \mathrm{mM}$ ( 1 time/ 2 weeks $)>\mathrm{DTPA}+\mathrm{N}$ (0.06 mM, 1 time/1 week) > 대조구> DTPA (0.5 mM, 1 time/ 3 months) > 농 가관행 처리구 (Conventional practice)의 순이었고, 대조구 (Control)에 비해 DTPA $0.06 \mathrm{mM}$ 로 1주일에 1회 처리한 시 험구[DTPA $0.06 \mathrm{mM}$ (1 time/ 1 week)]에는 43\%가 많았고, DTPA $0.13 \mathrm{mM}$ 로 2주에 1회 처리한 구[(DTPA $0.13 \mathrm{mM}$ (1 time/ 2 weeks)]에서는 17\%, DTPA $0.06 \mathrm{mM}$ 로 1주일에 1회 처리하면서 질소비료를 시용한 구[DTPA+N (0.06 mM, 1 time/ 1 week)]는 $12 \%$ 가 많았다. 오이 열매 개수의 대한 상대지수 는 대조구에 비해 DTPA $0.06 \mathrm{mM}$ (1 time/ 1 week)처리구 에서는 $18 \%$ 가 많았고, DTPA $0.13 \mathrm{mM}$ (1 time/2 weeks)처 리구에서 17\%, DTPA (0.06 mM, 1 time/1 week) + N]처리 구에서 $12 \%$ 가 많았다 (Table 2). 이로부터 킬레이트제의 처 리는 오이열매의 개수보다는 무게를 증가시키는 효과가 더 욱 큰 것으로 나타났고, 염류가 많은 토양에 질소비료의 시 용은 작물수량 측면에서 킬레이트제 단독처리보다 효과가 떨어졌다. 그리고 pot조건에서 DTPA의 처리한 토양에서 재 배한 배추의 수량이 대조구와 통계적으로 유의한 차이는 보 였지만 (Kim et al., 2012), 포장 조건에서는 주위환경과 토 양환경의 변이성이 크기 때문에 통계적으로 유의한 차이는 나타나지 않았다. DTPA (0.5 mM, 1 time/3 months)처리구 는 다른 처리구들보다 효과가 떨어졌는데, 포장조건에서 오 이생육 초기에 1 회 관주함으로 인해 토양에 집적된 양분과 균일하게 반응하지 못하였기 때문으로 판단된다.

오이가 흡수한 무기성분의 함량은 Table 3 와 같으며, 처 리들 간에는 통계적으로 유의한 차이는 나타내지 않았다. DTPA

Table 2. Fresh weight and number of fruits in cucumber plants at soils treated with various concentrations of DTPA in 2010.

\begin{tabular}{lcccc}
\hline \multicolumn{1}{c}{ Treatments } & $\begin{array}{c}\text { Weight of fresh } \\
\text { fruit/20 plants }\end{array}$ & $\begin{array}{c}\text { Relative } \\
\text { index }\end{array}$ & $\begin{array}{c}\text { Number of } \\
\text { fresh fruit/20 plants }\end{array}$ & $\begin{array}{c}\text { Relative } \\
\text { index }\end{array}$ \\
\hline & $\mathrm{kg}$ & $\%$ & & $\%$ \\
Control & $42 \pm 10 \mathrm{a}^{\dagger}$ & 100 & $232 \pm 56 \mathrm{a}$ & 100 \\
Conventional practice & $39 \pm 10 \mathrm{a}$ & 93 & $217 \pm 45 \mathrm{a}$ & 94 \\
DTPA(0.5 mM, 1 time/3 months) & $41 \pm 12 \mathrm{a}$ & 98 & $227 \pm 60 \mathrm{a}$ & 98 \\
DTPA(0.06 mM, 1 time/1 week) & $60 \pm 23 \mathrm{a}$ & 143 & $273 \pm 34 \mathrm{a}$ & 118 \\
DTPA(0.13 mM, 1 time/2 weeks) & $49 \pm 9 \mathrm{a}$ & 117 & $271 \pm 47 \mathrm{a}$ & 117 \\
DTPA(0.06 mM, 1 time/1 week) $+\mathrm{N}^{\uparrow}$ & $47 \pm 8 \mathrm{a}$ & 112 & $260 \pm 43 \mathrm{a}$ & 112 \\
\hline
\end{tabular}

${ }^{\dagger}$ Duncan's multiple range test $(\mathrm{p}<0.05)$

${ }^{\ddagger}$ Relative yield of control treatment.

${ }^{\mathrm{N}} \mathrm{N}$ means nitrogen fertilizer 
Table 3. Inorganic element contents of cucumber during treatment of a chelating agent in the farm-fields in the autumn season of 2010.

\begin{tabular}{|c|c|c|c|c|c|c|c|}
\hline Treatments & $\mathrm{T}-\mathrm{N}$ & $\mathrm{P}$ & $\mathrm{K}$ & $\mathrm{Ca}$ & $\mathrm{Mg}$ & $\mathrm{Fe}$ & Mn \\
\hline & \multicolumn{7}{|c|}{ - } \\
\hline Control & $4.1 \pm 1.0 \mathrm{a}^{\dagger}$ & $5.3 \pm 1.1 \mathrm{a}$ & $7.0 \pm 1.2 \mathrm{a}$ & $24.8 \pm 5.0 \mathrm{a}$ & $6.2 \pm 1.5 \mathrm{a}$ & $0.13 \pm 0.04 \mathrm{a}$ & $0.02 \pm 0.00 \mathrm{a}$ \\
\hline Conventional paracitce & $4.1 \pm 0.9 \mathrm{a}$ & $6.7 \pm 2.2 \mathrm{a}$ & $9.3 \pm 4.5 \mathrm{a}$ & $28.6 \pm 10.3 \mathrm{a}$ & $6.7 \pm 1.9 \mathrm{a}$ & $0.15 \pm 0.06 \mathrm{a}$ & $0.03 \pm 0.01 \mathrm{a}$ \\
\hline DTPA(0.5 mM, 1 time $/ 3$ months $)$ & $4.2 \pm 1.4 \mathrm{a}$ & $7.2 \pm 2.8 \mathrm{a}$ & $9.6 \pm 2.9 \mathrm{a}$ & $26.4 \pm 12.8 \mathrm{a}$ & $6.2 \pm 2.3 \mathrm{a}$ & $0.14 \pm 0.07 \mathrm{a}$ & $0.02 \pm 0.01 \mathrm{a}$ \\
\hline DTPA(0.06 mM, 1 time/1 week) & $4.5 \pm 0.6 \mathrm{a}$ & $5.8 \pm 0.6 \mathrm{a}$ & $10.4 \pm 3.6 \mathrm{a}$ & $30.8 \pm 7.6 \mathrm{a}$ & $7.0 \pm 1.8 \mathrm{a}$ & $0.15 \pm 0.05 \mathrm{a}$ & $0.04 \pm 0.02 \mathrm{a}$ \\
\hline DTPA(0.13 mM, 1 time/2 weeks $)$ & $4.8 \pm 1.0 \mathrm{a}$ & $6.3 \pm 1.3 \mathrm{a}$ & $9.0 \pm 2.2 \mathrm{a}$ & $29.4 \pm 4.0 \mathrm{a}$ & $7.1 \pm 2.4 \mathrm{a}$ & $0.13 \pm 0.00 \mathrm{a}$ & $0.04 \pm 0.02 \mathrm{a}$ \\
\hline DTPA $(0.06 \mathrm{mM}, 1$ time $/ 1$ week $)+\mathrm{N}^{\ddagger}$ & $4.8 \pm 0.7 \mathrm{a}$ & $6.0 \pm 2.2 \mathrm{a}$ & $10.2 \pm 4.1 \mathrm{a}$ & $26.7 \pm 11.4 \mathrm{a}$ & $6.1 \pm 1.9 \mathrm{a}$ & $0.12 \pm 0.013 \mathrm{a}$ & $0.03 \pm 0.02 \mathrm{a}$ \\
\hline
\end{tabular}

${ }^{\dagger}$ Duncan's multiple range test $(\mathrm{p}<0.05)$

${ }^{\ddagger} \mathrm{N}$ means nitrogen fertilizer
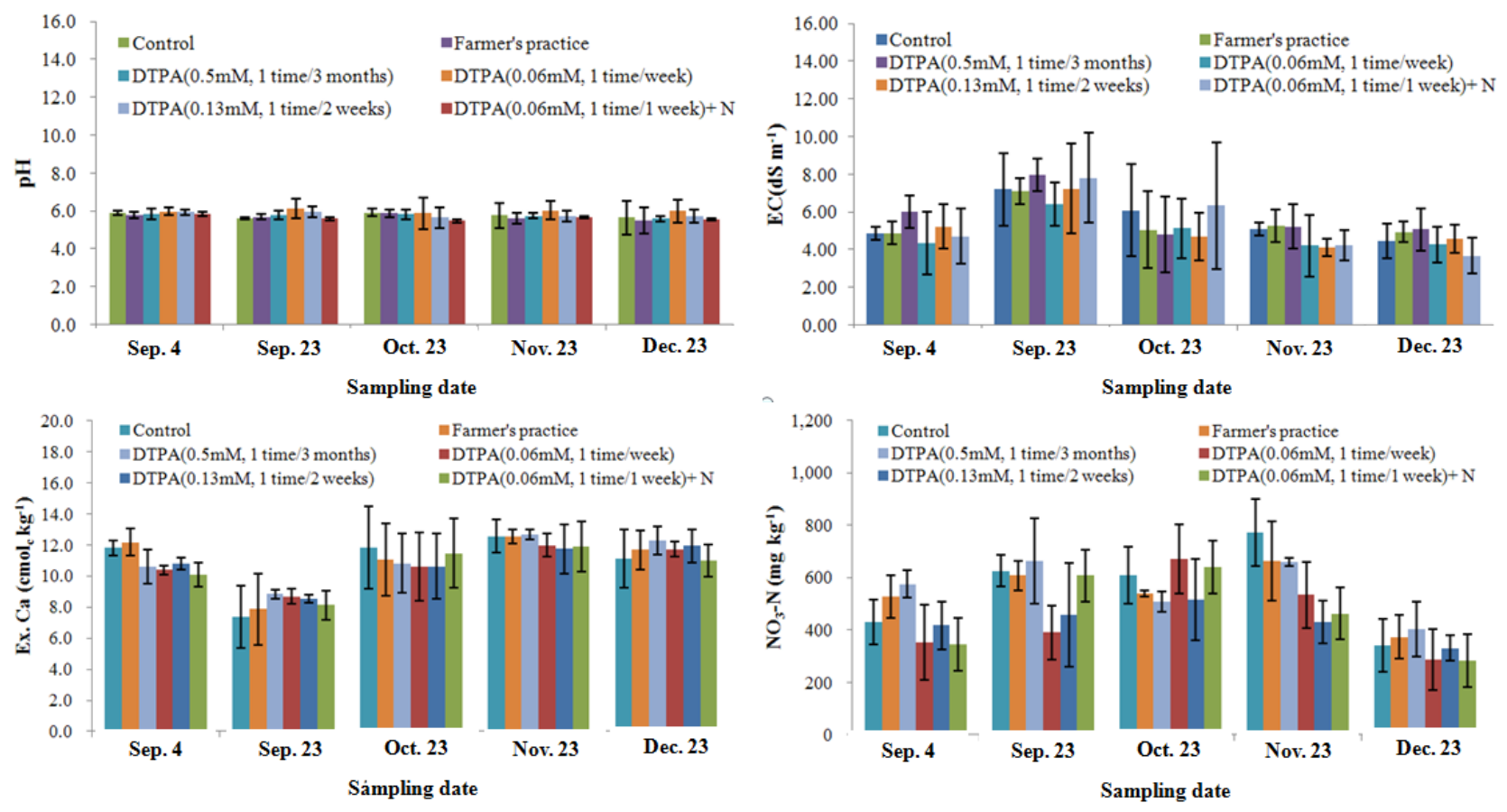

Fig. 1. Contents of pH, EC, Ex. Ca, and $\mathrm{NO}_{3}-\mathrm{N}$ by sampling date in soils cultivated with cucumber in the autumn season of 2010.

$0.06 \mathrm{mM}$ ( 1 time/1 week)처리구와 DTPA $0.13 \mathrm{mM}$ (1 time/ 2 weeks)처리구에서 작물체 (잎+줄기+열매) 중에 $\mathrm{T}-\mathrm{N}, \mathrm{K}$, $\mathrm{Ca}, \mathrm{Mg}, \mathrm{Fe}, \mathrm{Mn}$ 등의 흡수량이 증가하였다. DTPA $0.06 \mathrm{mM}$ 농도로 1 주일에 1 회를 처리할 경우 대조구에 비해 $\mathrm{T}-\mathrm{N}$ 과 $\mathrm{P}$ 는 1.1배, $\mathrm{K}$ 는 1.5 배, $\mathrm{Ca}$ 는 1.1 배, $\mathrm{Mg}$ 과 $\mathrm{Fe}$ 은 1.2배, $\mathrm{Mn}$ 은 2.0 배 증가한 양이었고, DTPA를 $0.13 \mathrm{mM}$ (1 time/2 weeks) 처리구에서도 대조구에 비해 1.1 2.0배까지 증가하였다. 토양 중 미량원소의 유효도를 증가시키는 킬레이트제의 상 대적 효율성은 안정화상수에 따라 달라지며, $\mathrm{Fe}^{3+}>\mathrm{Cu}^{2+}>$ $\mathrm{Zn}^{2+}>\mathrm{Mn}^{2+}>\mathrm{Fe}^{2+}$ 의 순서로 안정화상수가 높기 때문이다 (Tuntiwiwut, 1982). Abdulla and Smith (1963)는 배추에서 대조구보다 $\mathrm{Ca}, \mathrm{Mg}, \mathrm{P}, \mathrm{Fe}, \mathrm{Cu}, \mathrm{Zn}$ 의 함량이 증가하였다 고 하였고, Kim et al. (2012)은 N, P, K, Ca, Mg, Fe, Cu의 성분이 증가하였다는 보고가 본 실험과 비슷한 경향을 나타
내었다. DTPA + N (0.06 mM, 1 time/1 week)처리구에서는 DTPA만을 처리한 구[DTPA (0.06 mM, 1 time/1 week), DTPA (0.13 mM, 1 time/2 weeks)처리구에 비해 흡수량이 크지 않았고, 이를 통해 염류가 집적된 토양에서 오이를 재 배 시 추가적인 질소비료의 투입은 오이의 양분 흡수량을 증가시키지 못한다는 것을 알 수 있었다.

킬레이트제인 DTPA를 처리하고 오이를 재배하는 동안의 토양의 화학성을 살펴 본 결과, 채취시기가 같으면 토양 $\mathrm{pH}, \mathrm{EC}, \mathrm{Ex} . \mathrm{Ca}, \mathrm{NO}_{3}-\mathrm{N}$ 에서 처리간에 큰 차이가 없었다 (Fig. 1). 이것은 토양으로부터 오이가 흡수한 양분의 양에 의한 차이보다 포장조건에서 토양화학성의 불균일성 등의 요인에 의한 영향이 컸기 때문으로 판단된다. 토양의 $\mathrm{EC}$ 와 $\mathrm{NO}_{3}-\mathrm{N}$ 는 점점 증가하였다가 수확시기 (Dec. 14)로 갈수록 감소하는 경향이었고, 토양의 $\mathrm{EC}$ 는 $\mathrm{NO}_{3}-\mathrm{N}$ 함량에 큰 영향 
을 받기 때문이다. Pot조건에서는 생육후기에 처리간의 양 분감소로 인한 차이가 확인되었지만 (Kim et al., 2012), 포 장조건에서는 처리간에 차이가 없었다.

2011년 봄 여름 작기 재배 봄작기에 오이 열매의 총 무게와 개수는 Fig. 2 와 같다. 처리간에 통계적인 차이는 없 었지만, 오이 열매의 총무게는 DTPA $0.06 \mathrm{mM}$ 처리구에서 대조구에 비해 $12 \%$ 까지 증가하였고, DTPA $0.09 \mathrm{mM}$, DTPA $0.13 \mathrm{mM}$ 처리구에서는 대조구에 비해 $5 \sim 6 \%$ 까지 높아졌으 며, 비료가 투입된 처리구 (NPK, $1 / 2 \mathrm{NPK}$ )와 비료와 킬레 이트제인 DTPA를 혼합하여 처리한 구 (DTPA $0.06 \mathrm{mM}+$ $\mathrm{NPK}, \mathrm{DTPA} 0.06 \mathrm{mM}+1 / 2 \mathrm{NPK}$ )에서는 대조구에 비해 수 량이 증가하지 않았다. 그리고 오이 열매의 개수는 DTPA $0.06 \mathrm{mM}$ 처리구와 DTPA $0.13 \mathrm{mM}$ 처리구는 대조구보다 $9 \%$ 증가하는 것으로 나타나, 2011년 가을 작기 재배 실험과 마찬가지로 킬레이트제인 DTPA를 토양에 투입하는 것은 오이의 개수보다는 무게를 증가시키는데 영향을 미쳤다.

봄작기에 오이 작물체 (잎+줄기+열매)의 무기성분량은 Table
4와 같다. DTPA 0.19 mM 처리구가 작물체 중 $\mathrm{Ca}$ 과 $\mathrm{Mg}$ 함 량이 높았고, 이들 성분은 화학비료 투입구 (NPK), 킬레이 트제와 화학비료 혼합구 (DTPA $0.06 \mathrm{mM}+1 / 2 \mathrm{NPK}$, DTPA $0.06 \mathrm{mM}+\mathrm{NPK})$ 와 통계적으로 유의적인 차이가 인정되었 으며, 미량원소 중 $\mathrm{Cu}$ 함량이 화학비료 투입구 $(1 / 2 \mathrm{NPK}$, $\mathrm{NPK})$ 와 통계적으로 유의적인 차이가 있었다. 그리고 DTPA $0.19 \mathrm{mM}$ 구에서 작물체 중의 $\mathrm{Ca}, \mathrm{Mg}, \mathrm{Cu}$ 함량은 화학비료 혼합구와 화학비료 투입구보다 1.2 배 많이 흡수한 것으로 나타났다. 오이수량이 많은 DTPA $0.06 \mathrm{mM}$ 구에서 작물체 의 양분 흡수량은 대조구에 비해 $\mathrm{T}-\mathrm{N}, \mathrm{K}$ 는 1.1 배, $\mathrm{P}, \mathrm{Mg}$ 는 1.04 배, $\mathrm{Fe}, \mathrm{Zn}$ 은 1.5배, $\mathrm{Cu}$ 는 1.2배로 많았지만, 통계적인 차이는 없었다. DTPA와 화학비료 혼합구, 화학비료 처리구 에서는 작물체의 양분흡수량은 DTPA만을 처리한 구에 비 해 적었으며, 이를 통해 토양의 양분이 집적된 토양에서 오 이를 재배할 경우 추가적인 화학비료의 토양의 투입은 작물 의 양분흡수량 증가에 기여하지 못하는 것으로 분석되었다.

킬레이트제를 장기적으로 투입함에 따른 오이 수량의 영 향을 살펴보고자 봄작기 (2월 7일 7월 4일)와 여름작기 (7월
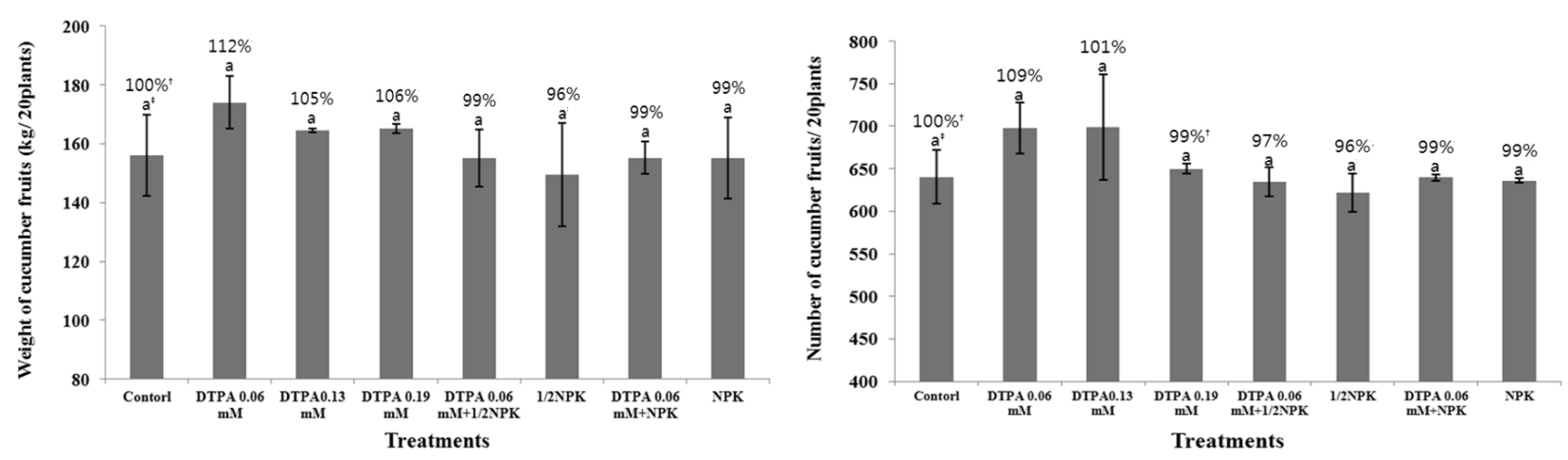

Fig. 2. Fresh weight and number of fruits in cucumbers cultivated in soils applied with DTPA and NPK fertilizers at the farm-fields in the spring season of $2011 .{ }^{\dagger}$ Relative yield of control treatment, ${ }^{\ddagger}$ Duncan's multiple range test $(\mathbf{p}<0.05)$.

Table 4. Uptake amount of inorganic contents in cucumber treated a chelating agent during spring season of cucumber at the farm-fields in 2011.

\begin{tabular}{|c|c|c|c|c|c|c|c|c|}
\hline Treatments & $\mathrm{T}-\mathrm{N}$ & $\mathrm{P}$ & $\mathrm{K}$ & $\mathrm{Ca}$ & $\mathrm{Mg}$ & $\mathrm{Fe}$ & $\mathrm{Mn}$ & $\mathrm{Cu}$ \\
\hline & & - & 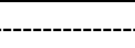 & ------------ g & g plant ${ }^{-1}$ & & & - \\
\hline Control & $360 \pm 37 \mathrm{a}^{\dagger}$ & $226 \pm 19 \mathrm{ab}$ & $925 \pm 24 a$ & $361 \pm 19 \mathrm{abc}$ & $114 \pm 15 \mathrm{abc}$ & $6.6 \pm 4.4 \mathrm{ab}$ & $0.31 \pm 0.16 \mathrm{a}$ & $0.206 \pm 0.004 \mathrm{ab}$ \\
\hline DTPA $0.06 \mathrm{mM}$ (2 times/1week) & $397 \pm 19 a$ & $235 \pm 6 a$ & $998 \pm 133 a$ & $352 \pm 27 \mathrm{abc}$ & $118 \pm 2 \mathrm{abc}$ & $9.9 \pm 1.2 \mathrm{a}$ & $0.41 \pm 0.02 \mathrm{a}$ & $0.247 \pm 0.022 \mathrm{a}$ \\
\hline DTPA $0.13 \mathrm{mM}$ (2 times/1week) & $361 \pm 1 \mathrm{a}$ & $236 \pm 4 a$ & $830 \pm 175 a$ & $401 \pm 22 \mathrm{ab}$ & $123 \pm 2 \mathrm{ab}$ & $4.2 \pm 0.4 \mathrm{ab}$ & $0.24 \pm 0.02 \mathrm{a}$ & $0.217 \pm 0.018 \mathrm{ab}$ \\
\hline DTPA $0.19 \mathrm{mM}$ (2 times/1week) & $361 \pm 23 \mathrm{a}$ & $245 \pm 14 \mathrm{a}$ & $895 \pm 10 \mathrm{a}$ & $420 \pm 9 a$ & $133 \pm 3 a$ & $4.2 \pm 0.6 \mathrm{ab}$ & $0.27 \pm 0.02 \mathrm{a}$ & $0.237 \pm 0.000 \mathrm{a}$ \\
\hline $\begin{array}{l}\text { DTPA } 0.06 \mathrm{mM}+1 / 2 \mathrm{NPK}^{\ddagger} \\
(2 \text { times } / 1 \text { week })\end{array}$ & $355 \pm 31 \mathrm{a}$ & $220 \pm 16 \mathrm{ab}$ & $887 \pm 97 a$ & $337 \pm 42 b c$ & $99 \pm 6 b c$ & $6.9 \pm 1.9 \mathrm{ab}$ & $0.31 \pm 0.08 \mathrm{a}$ & $0.198 \pm 0.032 \mathrm{ab}$ \\
\hline $1 / 2 \mathrm{NPK}$ & $349 \pm 68 \mathrm{a}$ & $207 \pm 8 \mathrm{ab}$ & $882 \pm 90 \mathrm{a}$ & $345 \pm 15 b c$ & $109 \pm 11 \mathrm{abc}$ & $6.8 \pm 2.6 \mathrm{ab}$ & $0.29 \pm 0.08 \mathrm{a}$ & $0.169 \pm 0.031 b$ \\
\hline $\begin{array}{l}\text { DTPA } 0.06 \mathrm{mM}+\mathrm{NPK} \\
(2 \text { times } / 1 \text { week })\end{array}$ & $363 \pm 50 \mathrm{a}$ & $184 \pm 31 b$ & $887 \pm 90 \mathrm{a}$ & $327 \pm 49 \mathrm{c}$ & $100 \pm 20 b c$ & $3.9 \pm 1.2 \mathrm{~b}$ & $0.32 \pm 0.03 \mathrm{a}$ & $0.202 \pm 0.017 \mathrm{ab}$ \\
\hline NPK & $333 \pm 64 a$ & $203 \pm 29 a b$ & $882 \pm 168 \mathrm{a}$ & $343 \pm 8 b c$ & $96 \pm 9 \mathrm{c}$ & $6.8 \pm 4.1 \mathrm{ab}$ & $0.34 \pm 0.11 \mathrm{a}$ & $0.168 \pm 0.047 b$ \\
\hline
\end{tabular}

${ }^{\dagger}$ Duncan's multiple range test $(\mathrm{p}<0.05)$

${ }^{\ddagger} \mathrm{NPK}$ means nitrogen, phosphate, and potassium fertilizer 
Table 5. Relationship between relative yield and total amount of DTPA added during spring (Feb. $5 \sim$ Jul. 4) and summer seasons (Jul. 6 Sep. 2) under polytunnel greenhouse in 2011.

\begin{tabular}{lcccccc}
\hline \multirow{2}{*}{\multicolumn{2}{c}{ Treatments }} & \multicolumn{2}{c}{ Spring season } & \multicolumn{2}{c}{ Summer season } & \multicolumn{2}{c}{ Total amount of } \\
\cline { 2 - 5 } & Amount of DTPA & Relative yield ${ }^{\dagger}$ & Amount of DTPA & Relative yield & DTPA \\
\hline Control & $\mathrm{mM}$ & $\%$ & $\mathrm{mM}$ & $\%$ & $\mathrm{mM}$ \\
NPK & - & $100 \mathrm{a}^{\ddagger}$ & - & $100 \mathrm{a}$ & - \\
DTPA $0.06 \mathrm{mM}(2$ times/ 1 week $)$ & 1.56 & $100 \mathrm{a}$ & - & $100 \mathrm{a}$ & - \\
DTPA $0.13 \mathrm{mM}(2$ times/ 1 week $)$ & 3.38 & $109 \mathrm{a}$ & 0.96 & $90 \mathrm{ab}$ & 2.52 \\
DTPA $0.19 \mathrm{mM}(2$ times/ 1 week $)$ & 4.94 & $109 \mathrm{a}$ & 2.08 & $75 \mathrm{~b}$ & 5.46 \\
\hline
\end{tabular}

${ }^{\dagger}$ Relative yield of control treatment.

${ }^{\ddagger}$ Duncan's multiple range test $(\mathrm{p}<0.05)$

"NPK means nitrogen, phosphate, and potassium fertilizer

6일 9월 2일)에 걸친 실험을 수행한 결과, 킬레이트제를 봄부터 여름까지 1 주일에 2 회로 계속 투입한 구인 DTPA $0.13 \mathrm{mM}$, DTPA $0.19 \mathrm{mM}$ 처리구는 대조구보다 수량이 각 각 25 26\%까지 낮아졌고, 화학비료를 넣은 NPK 처리구는 대조구와 비슷한 수량이 생산되었다 (Table 5). DTPA 0.19 $\mathrm{mM}$ 처리구의 봄작기에 DTPA 총 투입량은 $4.94 \mathrm{mM}$ 로 수량 은 대조구와 차이가 없었으나, 여름작기로 갈수록 수량은 더욱 감소하였으며, 이것은 DTPA $4.94 \mathrm{mM}$ 농도 이후에서 는 생육저해가 발생하였다. 이는 토양에 DTPA가 미생물의 작용으로 생분해되지 못하고 잔류하여 영향을 미쳤기 때문 이라 생각된다. Means et al. (1980)은 DTPA가 빛이 있는 조건에서 173 일 후에 $5 \%$, 어두운 조건에서 $47 \%$ 가 잔류된다 고 하였고, Bolton et al. (1993)은 DTPA를 토양과 반응시킨 후 115 일이 지나면 $74 \%$, 유기물질인 탄소를 첨가해 줄 경우 잔류하는 양이 더욱 많다고 보고하였다. 이번 포장실험은 150 일 동안에 이루어진 것으로, 고농도의 DTPA가 토양에 남았을 것으로 추정된다. 그리고 Wallace et al. (1974)는 토 양에 투입된 고농도의 킬레이트제는 식물에게 독성을 나타 내고, 이것은 식물의 뿌리가 양이온을 흡수하는 것을 억제 하며 일부 미량원소의 결핍을 유도한다고 보고하였다. 이처 럼 킬레이트제 토양 투입에 따른 토양의 잔류성과 작물의 생육에 미치는 영향을 살펴보기 위해 $3 \sim 4$ 년의 장기적인 관 점에서 더욱 연구할 필요가 있다고 생각된다.

봄작기에 모든 처리구에서 토양의 $\mathrm{EC}$ 와 $\mathrm{NO}_{3}-\mathrm{N}$ 함량은 킬레이트제 처리전 (2월 7일)보다 킬레이트제가 처리된 이 후인 오이를 최종 수확한 시기 (7월 4일)에 가장 많이 낮아 졌다 (Fig. 3). 그리고 토양의 $\mathrm{EC}$ 와 $\mathrm{NO}_{3}-\mathrm{N}$ 함량은 오이의 생육기간 동안에 유사한 경향으로 변화되었다 이것은 토양 의 $\mathrm{EC}$ 는 $\mathrm{NO}_{3}-\mathrm{N}$ 의 영향을 크게 받았기 때문인 것으로 판단 된다. $\mathrm{NH}_{4}-\mathrm{N}$ 는 킬레이트제 처리전 (2월 7일)보다 최종 수 확기 (7월 4일)에 가장 많이 증가하였고, 이는 여름철에 지온 의 상승으로 토양 중 유기물질의 급격한 분해로 인해 $\mathrm{NH}_{4}-\mathrm{N}$
가 크게 증가한 것으로 생각된다. Ex. Ca 함량도 킬레이트 제 처리 전 (2월 7일)보다 낮아졌으며, 가장 많이 낮아진 것 은 가을작기의 수확기 (9월 2일)였다. NPK 처리구에서는 식물이 흡수한 양보다 비료의 공급이 많아 오히려 토양의 $\mathrm{EC}$ 는 증가하였다. 농가의 포장조건에서는 처리구의 위치에 따라 토양 화학성의 변이가 더 크기 때문에 처리간에 통계 적인 유의성은 나타나지 않았다.

봄작기 (2월 6 월)에 시설오이를 재배하는 농가에서 관행 구 대비 비용절감율을 비교해보면, DTPA $0.06 \mathrm{mM}$ (1 time/ 1 week), DTPA $0.06 \mathrm{mM}$ (2 time/1 week), DTPA (0.06 mM, 1 time/ 1 week) + N에서 각각 $67,34,59 \%$ 로 DTPA 0.06 $\mathrm{mM}$ (1 time/1 week) 처리구에서 가장 높았다 (Table 6). 또 한편으로 대조구는 자원 투입 비용이 없고, 킬레이트제 처 리구와 수량에서 통계적으로 유의성이 없어 대조구가 우수 하다고 생각할 수 있다. 그러나, 구체적인 자료를 제시하지 않 았지만, 킬레이트제 처리구 중 효과가 제일 높은 DTPA 0.06 $\mathrm{mM}$ (1 time/1 week) 처리구와 대조구를 자원 투입과 작물 수량의 2 가지 측면에서 경제성 분석을 한 결과 DTPA 0.06 $\mathrm{mM}$ 처리구가 대조구에 비해 $17 \%$ 의 이익이 발생하였고, 재 배환경의 급격한 변화 등 환경이 불량해지면 물만 주고 재 배한 대조구에서는 작물 생육 장해가 발생할 가능성이 높기 때문에 농가 포장에서 활용성이 낮다고 생각된다. 이러한 점을 고려해 볼 때 DTPA $0.06 \mathrm{mM}$ 의 농도로 1주일에 1 회로 처리하는 것이 시설재배지의 집적된 염류를 재활용하고 농 가 소득에서 이익이 발생하며, 실제 농업인의 포장에서 활 용성이 더 높다고 생각한다.

염류가 집적된 시설재배지에서 1 작기 또는 2 작기 동안의 킬 레이트제를 투입한 결과 오이의 수량, 흡수량, 그리고 토양화 학성 측면에서 처리간에 통계적으로 유의한 차이를 나타내지 않았지만, 3 4년의 장기적인 시험을 수행할 경우 처리간에 유 의성 있는 킬레이트제 처리효과가 나타날 수 있을 것으로 생 각되며, 비료를 투입하지 않고도 토양에 저장된 양분을 잘 활 

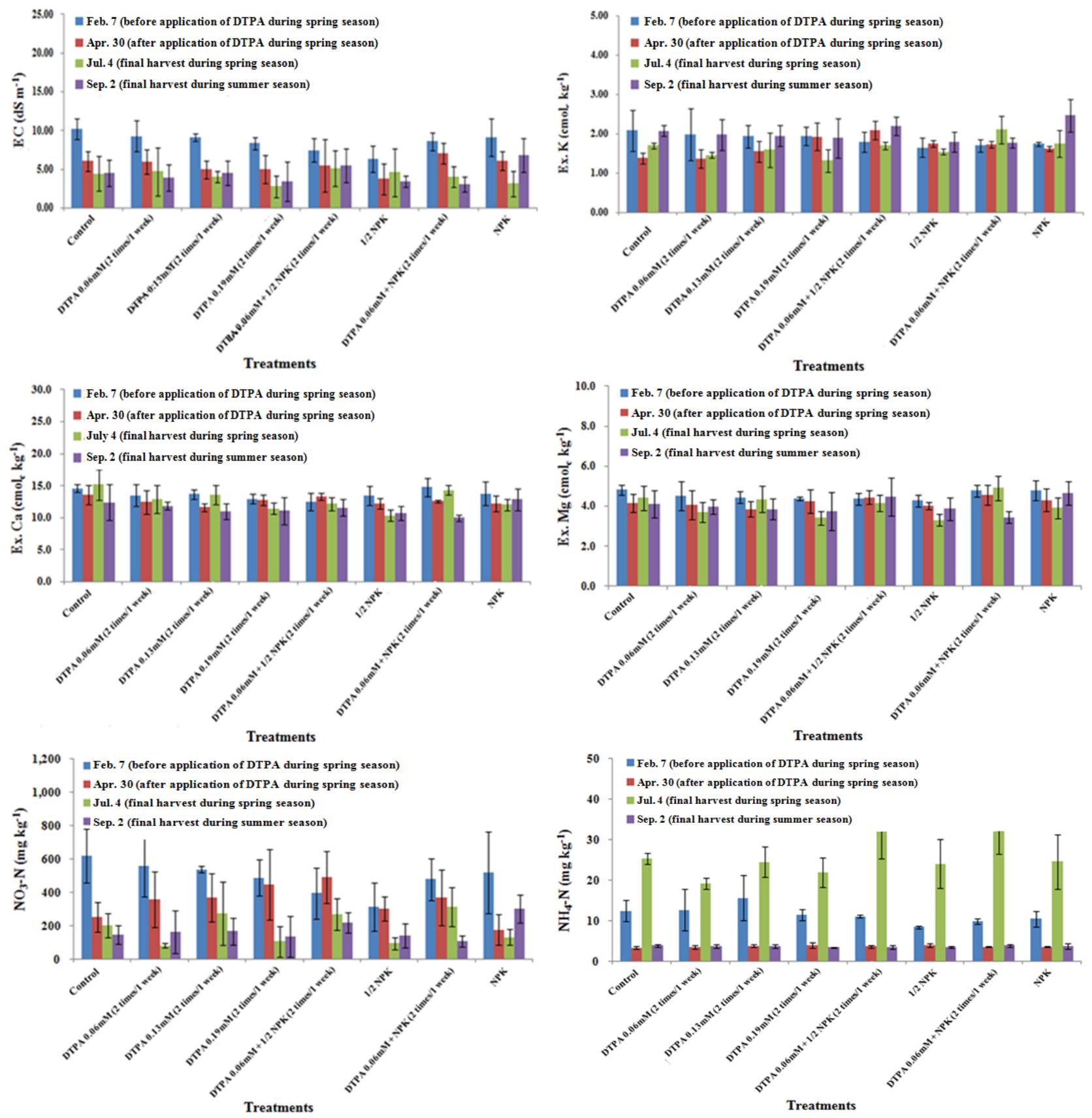

Fig. 3. Changes of EC, Ex. K, Ex. Ca, Ex, Mg, $\mathrm{NO}_{3}-\mathrm{N}$, and $\mathrm{NH}_{4}-\mathrm{N}$ in soil treated with chelates by soil sampling time in 2011 . Feb. 7 (before application of a chelate), Apr. 30, Jul. 4 (final harvest during spring season), Sep. 2 (final harvest during summer season).

Table 6. Comparison between cost of DTPA and fertilizers by conventional practice during cropping system from February to June.

\begin{tabular}{|c|c|c|c|c|}
\hline \multirow{2}{*}{ Treatments } & \multicolumn{3}{|c|}{ Input cost } & \multirow{2}{*}{ Saving cost } \\
\hline & DTPA & Inorganic fertilizers $^{\dagger}$ & Total & \\
\hline & 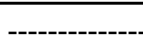 & - - won $10 \mathrm{a}^{-1}$ & ------- & --- \% --- \\
\hline Conventional practice & - & 355,425 & 355,425 & - \\
\hline DTPA $0.06 \mathrm{mM}$ (1 time/1 week) & 117,504 & - & 117,504 & 67 \\
\hline DTPA $0.06 \mathrm{mM}(2$ times $/ 1$ week $)$ & 235,008 & - & 235,008 & 34 \\
\hline DTPA $(0.06 \mathrm{mM}, 1$ time $/ 1$ week $)+\mathrm{N}^{\pi}$ & 117,504 & 29,811 & 147,315 & 59 \\
\hline
\end{tabular}

${ }^{\dagger}$ Data from Agricultural income information of 2010, RDA.

${ }^{\natural} \mathrm{N}$ means nitrogen fertilizer 
용할 수 있기 때문에 토양에 염류집적을 감소시킬 수 있으며 농가의 안정적인 작물생산에도 도움이 될 것으로 판단되었다.

\section{Conclusions}

염류가 집적된 시설재배지에서 토양 화학성 변화 및 오 이생육에 미치는 영향을 분석하고자 킬레이트의 처리농도 및 관주횟수를 달리하여 수행하였다. 그 결과 킬레이트제 (DTPA) 처리 농도와 관주횟수별 오이 수량 및 토양 화학성 변화에 현저한 차이가 없었다. 그러나, DTPA $0.06 \mathrm{mM}$ 농 도를 1 주일에 1 회 간격으로 토양에 관주할 경우 비용 절감 효율이 $67 \%$ 로 가장 높게 평가되어 비료 사용량 감축에 가장 효과적이라 판단되었다. 한편, 본 연구결과를 통해서 볼 때 화학비료와 킬레이트제를 동시에 투입하면 작물생육을 촉 진하기 것보다 오히려 생육저해를 유발할 소지가 크며, DTPA가 고농도로 처리될 경우 작물 수량이 감소를 가져오 게 됨으로 적정 농도를 사용하는 것이 매우 중요하다는 결 론을 도출할 수 있었다.

\section{References}

Abdulla, I. and M.S. Smith. 1963. Influence of chelating agents on the concentration of some nutritions for plants growing in soil under acid and under alkaline conditions. J. Sci. Fd Agric. 14:98-109.

Bolton, H., S.W. Li, D.J. Workman, and D.C. Girvin. 1993. Biodegradation of Synthetic Chelates in Subsurface Sediments from the Southeast Coastal Plain. J. Environ. Qual. 22(1): 125-132.

Brown, J.C., L.O. Tiffin, and R.S. Holmes. 1960. Competition between chelating agents and roots as factor affecting absorption of iron and other ions by plant species. Plant Physiol. 35(6): 878-886.

Cao, A., A. Carucci, and T. Lai. 2007. Effect of biodegradable chelating agents on heavy metals phytoextraction with Mirabilis jalapa and on its associated bacteria. Eur. J. Soil Biol. 43:200-206.

Hong, P.K.A., C. Li, S.K. Banerji, and T. Regmi. 1999. Extraction, recovery, and biostability of EDTA for remediation of heavy metal-contaminated soil. J. Soil Contam. 8(1):81-103.

Jang, Y.H., S.H. Lee, Y.I. Park, and K.S. Lee. 2012. Characteristics of the absorption of cherry tomato by the application of chelated calcium and germanium. Korean J. Soil Sci. Fert. 45(5):787-791.

Kim, M.S., Y.H. Kim, M.Y. Roh, S.S. Gang, H.B. Yoon, and H.Y. Lee. 2012. Effect of chelating agents on growth of chinese cabbage and availability of nutrients in plastic film houses. Korean J. Soil Sci. Fert. 45(6):949-954.

Lee, S.T., M.K. Kim, Y,H. Lee, Y.S. Kim, and Y.B. Kim. 2011. Analysis of Fe-deficient inducing enzyme and required time for recovery of nutritional disorder by Fe-DTPA treatments in the Fe-deficient induced tomato cultivars. Korean J. Soil Sci. Fert. 44(5):767-772.

Lee, H.S., S.M. Hong, S.H. Ko, and K.S. Lee. 2012. EDTAenhanced electrokinetic removal of $\mathrm{Cu}$ and $\mathrm{Zn}$ from contaminated sandy soil. Korean Geo-environ. Society 3(1):37-45.

Lindsay, W.L. and W.A. Norvell. 1978. Development of a DTPA soil test for zinc, iron, manganese, and copper. Soil Sci. Soc. Amer. J. 42:421-428.

Means, J.L., T. Kucak, and D.A. Crerar. 1980. Relative degradation rates of NTA, EDTA and DTPA environmental implications. Environ. Pollut. (Series B) 1:45-60.

Nam, Y.H., I.S. Park, and J.W. Park. 2009. A study on remediation of pertroleum-contaminated soil using chemical oxidation. Korean Geo-Environ. Conference 405-413.

National Institute of Agricultural Science and Technology (NIAST). 2000. Methods of soil and plant analysis. National Institute of Agricultural Science and Technology, RDA, Suwon, Korea.

NIAST. 2006. Fertilizer Recommendation for crops (revision). National Institute of Agricultural Science and Technology, RDA, Suwon, Korea.

Oh, S.J., S.C. Kim, R.Y. Kim, Y.S. Ok, H.S. Yun, S.M. Oh, J.S. Lee, and J.E. Yang. 2012. Change of bioavailability in heavy metal contaminated soil by chemical amendment. Korean J. Soil Sci. Fert. 45(6):973-982.

Palmaa, L.D., P. Ferrantellia, C. Merlia, E. Petruccia, and I. Pitzolua. 2007. Influence of Soil Organic Matter on Copper Extraction from Contaminated Soil. Soil and Sediment Contamination 16:323-335.

RDA. 2008. Soil management manual for reduction of continuous cropping injury at the plastic film house. RDA., Suwon, Korea. RDA. 2010. Agricultural income information. RDA., Suwon, Korea.

RDA. 2013. Soil management technology for agricultural land. RDA., Suwon, Korea.

Tuntiwiwut, S.N. 1982. Effects of chelating agents on plant growth. Thesis (Ph. D.), Washington State University.

Wallace, A. 1963. Role of chelating agents on the availability of nutrients to plants. Soil Science Society Proceedings. 27:176-179.

Wallace, A., R.T. Muller, J.W. Cha, and G.V. Alexander. 1974. Soil $\mathrm{pH}$, excess lime, and chelating agent on micro nutrients in soybeans and bush beans. Agron. J. 66:698-700.

Weinstein, L.H., W.R. Robbins, and H.F. Perkins. 1954. Chelating agents and plant nutrition. Sci. 129:41-43. 